\title{
Nonlinear analysis of r.c. framed buildings retrofitted with elastomeric and friction bearings under near-fault earthquakes
}

\author{
Mirko Mazza
}

Received: 12 June 2015/Accepted: 8 October 2015/Published online: 4 November 2015

(c) The Author(s) 2015. This article is published with open access at Springerlink.com

\begin{abstract}
Reinforced concrete (r.c.) framed buildings designed in compliance with inadequate seismic classifications and code provisions present in many cases a high vulnerability and need to be retrofitted. To this end, the insertion of a base isolation system allows a considerable reduction of the seismic loads transmitted to the superstructure. However, strong near-fault ground motions, which are characterised by long-duration horizontal pulses, may amplify the inelastic response of the superstructure and induce a failure of the isolation system. The above considerations point out the importance of checking the effectiveness of different isolation systems for retrofitting a r.c. framed structure. For this purpose, a numerical investigation is carried out with reference to a six-storey r.c. framed building, which, primarily designed (as to be a fixed-base one) in compliance with the previous Italian code (DM96) for a medium-risk seismic zone, has to be retrofitted by insertion of an isolation system at the base for attaining performance levels imposed by the current Italian code (NTC08) in a high-risk seismic zone. Besides the (fixed-base) original structure, three cases of base isolation are studied: elastomeric bearings acting alone (e.g. HDLRBs); in-parallel combination of elastomeric and friction bearings (e.g. high-damping-laminated-rubber bearings, HDLRBs and steel-PTFE sliding bearings, SBs); friction bearings acting alone (e.g. friction pendulum bearings, FPBs). The nonlinear analysis of the fixed-base and base-isolated structures subjected to horizontal components of near-fault ground motions is performed for checking plastic conditions at the potential critical (end)
\end{abstract}

M. Mazza ( $₫)$

Dipartimento di Ingegneria Civile, Università della Calabria, Ponte Bucci, Cubo 39b, 87030 Arcavacata Di Rende, CS, Italy e-mail: mirko.mazza@gmail.com sections of the girders and columns as well as critical conditions of the isolation systems. Unexpected high values of ductility demand are highlighted at the lower floors of all base-isolated structures, while re-centring problems of the base isolation systems under near-fault earthquakes are expected in case of friction bearings acting alone (i.e. FPBs) or that in combination (i.e. SBs) with HDLRBs.

Keywords R.c. base-isolated structures - Elastomeric bearings $\cdot$ Friction bearings $\cdot$ Nonlinear dynamic analysis

\section{Introduction}

Reinforced concrete (r.c.) framed buildings designed for vertical loads only or in compliance with inadequate seismic classifications and seismic code provisions present in many cases a high seismic vulnerability and need to be retrofitted. For this purpose, different strategies can be followed: e.g. enhancing the strength and/or ductility capacity or modifying in a suitable way the distribution of the structural properties (mass, strength, stiffness). But sometimes these strategies may require very expensive and complex works. Alternatively, it can be easier and less expensive to use new retrofitting techniques, i.e. base isolation and/or supplemental damping, which aim to reducing the seismic effects by limiting the input energy and/or enhancing the energy dissipation capacity (Naeim and Kelly 1999; Christopoulos and Filiatrault 2006; Mazza and Vulcano 2007, 2011, 2013; 2014a, b, c; Corbi and Zaghw 2013; Corbi and de Barros 2013; Mazza 2014a, 2015a; Baratta et al. 2015). The main purpose of the present work is to improve the knowledge of the issues related to the choice and optimization of the base isolation systems more effective for the seismic retrofitting of r.c. framed 
structures located in a near-fault area, also considering the inelastic response of the superstructure to limit maximum and residual displacements of the isolators.

Base isolation of a structure allows a considerable reduction of the horizontal seismic loads transmitted to the superstructure. Different isolation strategies or their combination can be used (Braga et al. 2005; Mazza and Vulcano 2009, 2012; Ponzo et al. 2012; Mazza 2015b): more precisely, increasing the fundamental vibration period of the structure to shift it in the range of low spectral accelerations; limiting the maximum force transmitted to the superstructure depending on the friction coefficient. Therefore, the isolation systems are usually made with elastomeric bearings (e.g. HDLRBs), sometimes coupled in hybrid combination with steel-PTFE sliding bearings (SBs) or frictional pendulum bearings (FPBs). It is worth noting that in the case of an in-parallel combination of HDLRBs and SBs (i.e. ESBI structure) or FPBs acting alone (i.e. FPBI structure), the base-isolated structure, under particular conditions, behaves as a fixed-base structure: i.e. in the horizontal direction, until the friction threshold of the sliding bearings is not exceeded; in the vertical direction, providing the grid of girders placed at the level of the isolation system with a high stiffness and avoiding tensile loads and uplifts of the SBs and FPs. Alternatively, new shape-memory-alloy-rubber (Gur et al. 2013) and superelastic-friction (Ozbulut and Hurlebaus 2011) bearings could be adopted to improve the response of base-isolated structures under near-fault earthquakes.

However, a considerable increase of deformability of an isolated structure, in comparison with that of the corresponding fixed-base structure, may lead to an amplification in the structural response under strong near-fault ground motions, which are characterised by long-duration horizontal pulses. More specifically, the frequency content of the motion transmitted by the isolators to the superstructure can become critical for the superstructure when the pulse intensity is such that the superstructure undergoes plastic deformations; also, an amplification in the structural response is possible due to the long duration of the pulse (Mazza and Vulcano 2009, 2012). Moreover, failure of the isolation system can be induced by near-fault ground motions (Kasalanati and Constantinou 2005; Ryan and Chopra 2006).

The above considerations present the importance of checking the effectiveness of different isolation systems for retrofitting a r.c. framed structure. For this purpose, a numerical investigation is carried out with reference to a sixstorey r.c. framed building, which, primarily designed (as to be a fixed-base one) in compliance with an old Italian seismic code (DM96) for a medium-risk zone, has to be retrofitted by insertion of an isolation system at the base for attaining performance levels imposed by the current Italian code (NTC08) in a high-risk seismic zone. Besides the (fixed-base) primary structure, three cases of base isolation are studied: HDLRBs acting alone (i.e. EBI structure); in-parallel combination of HDLRBs and SBs (i.e. EFBI structure); FPBs acting alone, (i.e. FPBI structure). The nonlinear analysis of the fixed-base and base-isolated structures is carried out considering the horizontal components of seven near-fault ground motions selected in the Pacific Earthquake Engineering Research Center Database (2008) and scaled on the basis of the design hypotheses adopted for the test structure.

\section{Modelling of the base isolation structures}

\subsection{Base isolation system for the EBI structure}

The first base isolation system is constituted of elastomeric bearings acting alone. The HDLRBs provide energy dissipation and re-centring capability. Experimental results by Ryan et al. (2004) pointed out that the horizontal stiffness of a HDLRB (starting from $K_{\mathrm{H} 0}$ ) decreases with increasing vertical load $(P)$, while the corresponding vertical stiffness (starting from $K_{\mathrm{V} 0}$ ) decreases with increasing lateral deformation $\left(u_{\mathrm{H}}\right)$. To account for the observed behaviour, the two-spring-two-dashpot model shown in Fig. 1 can be adopted (Mazza and Vulcano 2012).

The nonlinear force-displacement laws for the horizontal $\left(F_{\mathrm{K}}-u_{\mathrm{H}}\right)$ and vertical $\left(P-u_{\mathrm{V}}\right)$ springs are given as (Naeim and Kelly 1999; Ryan et al. 2004)

$F_{\mathrm{K}}=K_{\mathrm{H}} u_{\mathrm{H}}=K_{\mathrm{H} 0}\left[1-\left(\frac{P}{P_{\mathrm{cr}}}\right)^{2}\right] u_{\mathrm{H}}$

$P_{\mathrm{K}}=K_{\mathrm{V}}\left(u_{\mathrm{V}}-\frac{\alpha_{\mathrm{b}}}{\alpha_{\mathrm{K} 0}} \frac{16}{\pi^{2} \phi_{\mathrm{b}} S_{2}} u_{\mathrm{H}}^{2}\right)$

where the compressive or tensile critical load $\left(P_{\text {cr }}\right)$ and the vertical stiffness $\left(K_{\mathrm{V}}\right)$ can be obtained according to
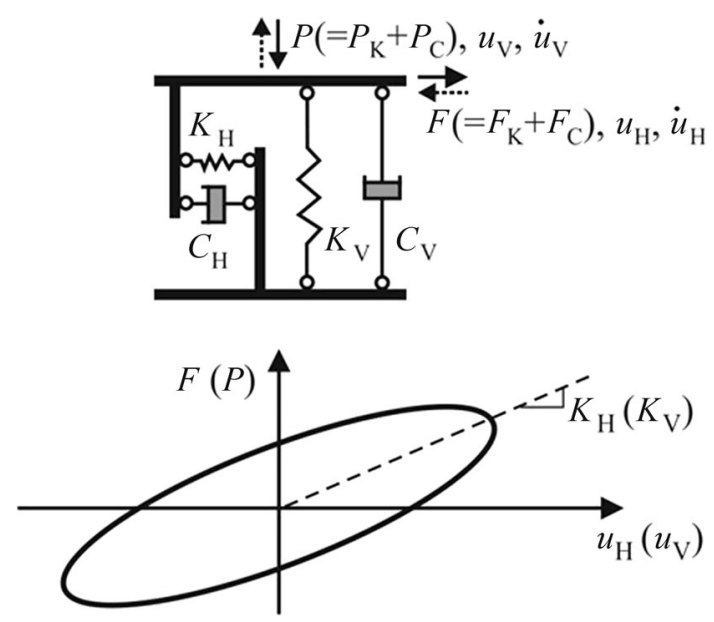

Fig. 1 Modelling of the base isolation system for the EBI structure: HDLRBs acting alone 
experimental observations (Ryan et al. 2004) and, after some manipulations, can be specialised for a circular bearing of diameter $\phi_{\mathrm{b}}$ as

$P_{\mathrm{cr}}= \pm \sqrt{P_{\mathrm{E}} \cdot K_{\mathrm{H} 0} \cdot h_{\mathrm{b}}}= \pm\left(\frac{\pi \phi_{\mathrm{b}}}{4}\right) K_{\mathrm{H} 0} \sqrt{\alpha_{\mathrm{K} 0}}$

$K_{\mathrm{V}}=\frac{K_{\mathrm{V} 0}}{1+48\left(\frac{u_{\mathrm{H}}}{\pi \phi_{\mathrm{b}}}\right)^{2}}$

where $\alpha_{\mathrm{b}}=h_{\mathrm{b}} / t_{\mathrm{r}}, h_{\mathrm{b}}$ and $t_{\mathrm{r}}$ being the total height of the bearing and the total thickness of the rubber, respectively (e.g. $\alpha_{\mathrm{b}}=1.2$ can be considered as a mean value); $S_{2}=\phi_{\mathrm{b}} / t_{\mathrm{r}}$ is the secondary shape factor (e.g. $S_{2} \geq 4$ is a conservative assumption); $P_{\mathrm{E}}$ the conventional Euler buckling load. Moreover, the linear forcevelocity laws for the horizontal $\left(F_{\mathrm{C}}-\dot{u}_{\mathrm{H}}\right)$ and vertical $\left(P_{\mathrm{C}}-\dot{u}_{\mathrm{V}}\right)$ dashpots in Fig. 1 are expressed as

$F_{\mathrm{C}}=C_{\mathrm{H}} \dot{u}_{\mathrm{H}} \cong\left(\frac{\xi_{\mathrm{H}} K_{\mathrm{H} 0} T_{1 \mathrm{H}}}{\pi}\right) \dot{u}_{\mathrm{H}}$

$P_{\mathrm{C}}=C_{\mathrm{V}} \dot{u}_{\mathrm{V}} \cong\left(\frac{\xi_{\mathrm{V}} K_{\mathrm{V} 0} T_{1 \mathrm{~V}}}{\pi}\right) \dot{u}_{\mathrm{V}}$

where $\xi_{\mathrm{H}}\left(\xi_{\mathrm{V}}\right)$ and $T_{1 \mathrm{H}}\left(T_{1 \mathrm{~V}}\right)$ represent the equivalent viscous damping ratio and the fundamental vibration period in the horizontal (vertical) direction, respectively.

\subsection{Base isolation system for the EFBI structure}

The second base isolation system is constituted of an inparallel combination of elastomeric (i.e. HDLRBs) and friction (i.e. SBs) bearings (Fig. 2). The SB basically depends on sliding velocity, contact pressure and temperature (Dolce et al. 2005). The frictional force at the sliding interface of the SBs can be expressed as

$F_{\mathrm{f}}=\mu \cdot P \cdot Z$

$\mu=\mu_{\max }-\left(\mu_{\max }-\mu_{\min }\right) \mathrm{e}^{-\alpha \dot{u}_{\mathrm{H}}}$

where $Z$ is a dimensionless hysteretic quantity ( $Z$ takes values of \pm 1 during sliding and less then unity during sticking) and $\mu$ is the coefficient of friction at sliding velocity $\dot{u}_{\mathrm{H}}$. The nonlinear force-displacement law in the horizontal direction is shown in Fig. 2, for the in-parallel combination of the HDLRBs and SBs. The corresponding equivalent viscous damping can be evaluated as

$\xi_{\mathrm{H}}=\frac{W_{\mathrm{h}, \mathrm{HDLRBs}}+W_{\mathrm{h}, \mathrm{SBs}}}{4 \pi\left(W_{\mathrm{s}, \mathrm{HDLRBs}}+W_{\mathrm{s}, \mathrm{SBs}}\right)}$

where $W_{\mathrm{s}}$ and $W_{\mathrm{h}}$ represent strain and hysteretic energies, respectively.

$W_{\mathrm{s}, \mathrm{HDLRBs}}=\frac{1}{2} \sum_{i=1}^{n_{\mathrm{HDLRBs}}} K_{\mathrm{H} i} \cdot u_{\mathrm{H}}^{2}$
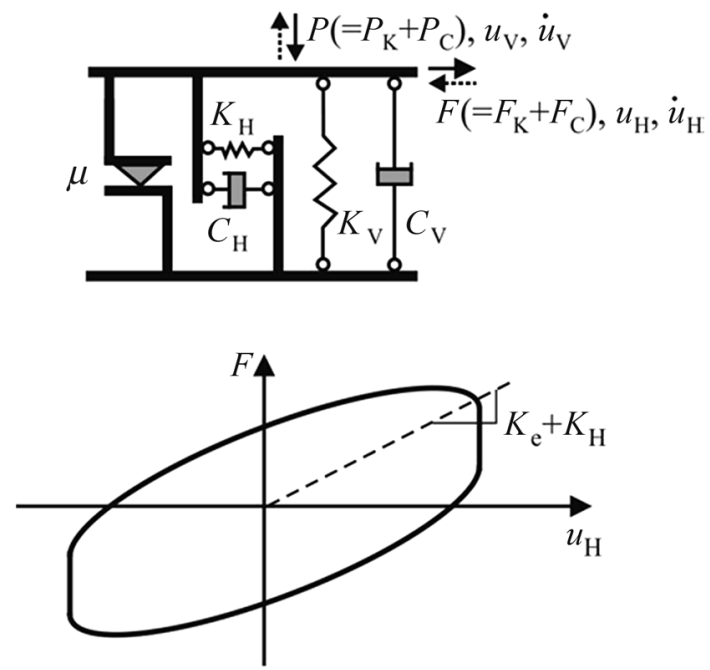

Fig. 2 Modelling of the base isolation system for the EFBI structure: combination of HDLRBs and SBs

$W_{\mathrm{h}, \mathrm{HDLRBs}}=4 \pi W_{\mathrm{s}, \mathrm{HDLRBs}} \cdot \xi_{\mathrm{H}, \mathrm{HDLRBs}}$

$W_{\mathrm{s}, \mathrm{SBs}}=\frac{1}{2} \sum_{i=1}^{n_{\mathrm{SBs}}} K_{\mathrm{e} i} \cdot u_{\mathrm{H}}^{2}=\frac{1}{2} \sum_{i=1}^{n_{\mathrm{SBs}}} \mu \cdot P_{i} \cdot u_{\mathrm{H}}$

$W_{\mathrm{h}, \mathrm{SBs}}=\sum_{i=1}^{n_{\mathrm{SBs}}} 4 \cdot \mu \cdot P_{i} \cdot u_{\mathrm{H}}$

being $K_{\mathrm{e}}$ the effective (secant) stiffness of the SBs at the horizontal displacement $u_{\mathrm{H}}$.

\subsection{Base isolation system for the FPBI structure}

The third base isolation system constitutes of friction pendulum bearings acting alone. The nonlinear force-displacement $(F-u)$ law of a FPB friction pendulum bearing can be represented considering the restoring $\left(F_{\mathrm{r}}\right)$ and frictional $\left(F_{\mathrm{f}}\right)$ forces shown in Fig. 3

$F=F_{\mathrm{r}}+F_{\mathrm{f}}=\left(\frac{P}{R}\right) u_{H}+\operatorname{sign}\left(\dot{u}_{\mathrm{H}}\right) \mu P$

where $R, u_{\mathrm{H}}$ and $\dot{u}_{\mathrm{H}}$ represent, respectively, the radius of curvature of the sliding surface, the horizontal displacement and the velocity of the device, while $P$ and $\mu$ are, respectively, the vertical load acting on the device and the friction coefficient (see Eq. 4b).

Finally, the effective stiffness and equivalent viscous damping related to the design displacement can be evaluated as

$K_{\mathrm{e}}=P\left(\frac{1}{R}+\frac{\mu}{u_{\mathrm{H}}}\right)$

$\xi_{\mathrm{H}}=\frac{2}{\pi} \frac{\mu R}{\mu R+u_{\mathrm{H}}}$ 


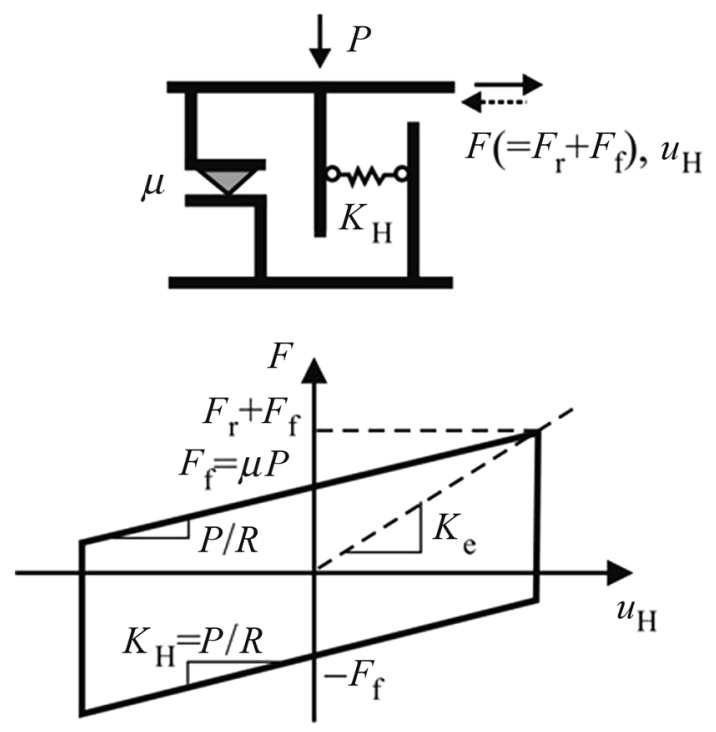

Fig. 3 Modelling of the base isolation system for the FPBI structure: FPBs acting alone

\subsection{Superstructure}

The r.c. frame members idealised by means of a twocomponent model, constituted of an elastic-plastic component and an elastic component, assuming a bilinear moment-curvature law. At each step of the analysis, the elastic-plastic solution is evaluated in terms of the initial state and the incremental load on the basis of a holonomic law, as a solution of the Haar-Kàrmàn principle (Mazza 2014a, b, 2015c). Specifically, by imposing plastic conditions on the bending moments $\left(m_{i}\right.$ and $\left.m_{j}\right)$ at the end sections $(i$ and $j$ ) of each frame element, the elastic-plastic solution can be obtained considering, among the equilibrated internal forces $\boldsymbol{m}=\left(m_{i}, m_{j}\right)^{\mathrm{T}}$, the one resulting closest to the elastic solution $\boldsymbol{m}_{\mathrm{E}}=\left(m_{\mathrm{E} i}, m_{\mathrm{E} j}\right)^{\mathrm{T}}$, satisfying the complementary energy minimum condition for the selfequilibrated internal forces $\left(\boldsymbol{m}-\boldsymbol{m}_{\mathrm{E}}\right)$. The above solution can be easily obtained by using the three-step algorithm illustrated in Fig. 4, where $M_{y 1}\left(M_{y 4}\right)$ and $M_{y 3}\left(M_{y 2}\right)$ represent, respectively, the yield moments producing tension at top and bottom of the end section $i(j)$.

\section{Layout and simulated design of the fixed-base original structures}

A typical six-storey residential building with a r.c. framed structure, whose symmetric plan is shown in Fig. 5, is considered as test structure. Masonry infill walls are considered as nonstructural elements regularly distributed along the perimeter and in elevation. A simulated design of

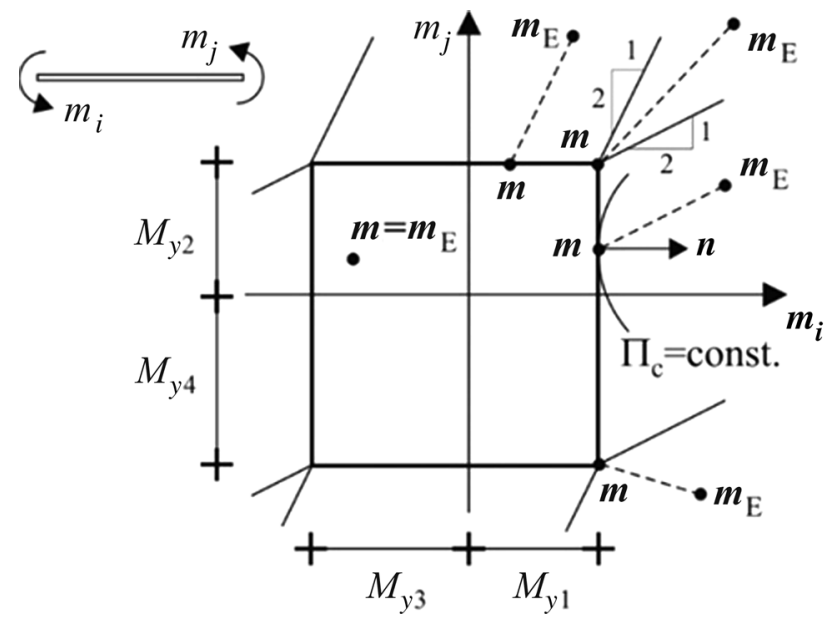

Fig. 4 Elastic-plastic solution according to Haar-Kàrmàn principle

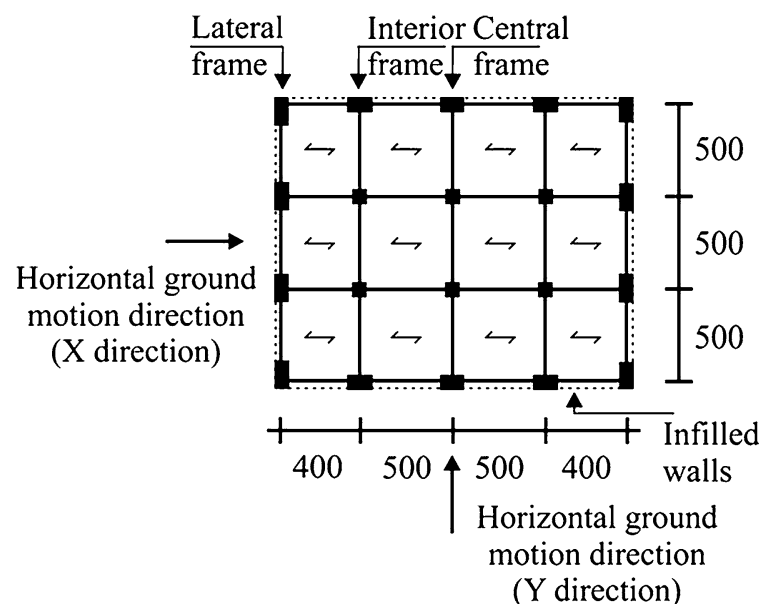

(a) Plan.

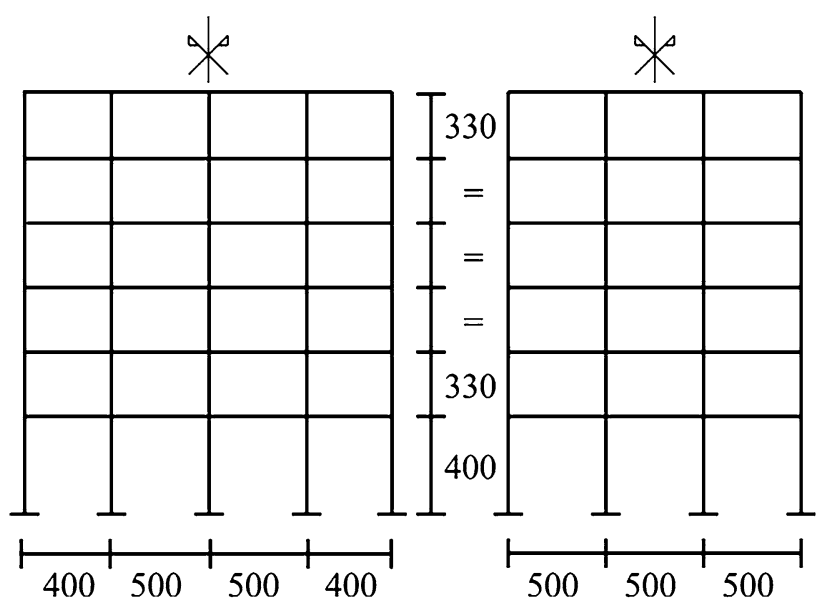

(b) Elevation (X direction) (c) Elevation ( $\mathrm{Y}$ direction)

Fig. 5 Fixed-base original structure (dimensions in $\mathrm{cm}$ ) 
the original framed building, is carried out in accordance with the previous Italian seismic code (DM96), for a medium-risk seismic region (seismic coefficient: $C=0.07$ ) and a typical subsoil class (main coefficients: $R=\varepsilon=\beta=1$ ). The gravity loads for the r.c. framed structure are represented by a dead load of $4.2 \mathrm{kN} / \mathrm{m}^{2}$ on the top floor and $5.0 \mathrm{kN} / \mathrm{m}^{2}$ on the other floors, and a live load of $2.0 \mathrm{kN} / \mathrm{m}^{2}$ on all the floors; an average weight of about $2.7 \mathrm{kN} / \mathrm{m}^{2}$ is considered for the masonry infill walls. Concrete cylindrical compressive strength of $25 \mathrm{~N} / \mathrm{mm}^{2}$ and steel reinforcement with yield strength of $375 \mathrm{~N} / \mathrm{mm}^{2}$ are considered. The corresponding floor masses $\left(m_{i}\right)$ are reported in Table 1.

The design is carried out to comply with the ultimate limit states. Detailing for local ductility is also imposed to satisfy minimum conditions for the longitudinal bars of the r.c. frame members: for the girders, a tension reinforcement ratio nowhere less than $0.37 \%$ is provided and a compression reinforcement not less than half of the tension reinforcement is placed at all sections; for a section of each column a minimum steel geometric ratio of $1 \%$ is assumed, supposing that the minimum reinforcement ratio corresponding to one side of the section be about $0.35 \%$.

The geometric dimensions of the lateral, interior and central frames are shown in Fig. 5b, c. Cross section of two typologies of girders (i.e. deep and flat) and three typologies of columns (i.e. corner, perimeter and central) are reported in Tables 1 and 2. It is worth noting that interior flat girders are placed only along the $X$ direction, parallel to the floor slab orientation. Finally, the dynamic properties of the six main vibration modes are reported in Table 3: i.e. vibration period $\left(T_{i}\right)$; effective masses in the $\mathrm{X}$ (i.e. $m_{\mathrm{E}, X}$ ) and $\mathrm{Y}$ (i.e. $m_{\mathrm{E}, Y}$ ) directions, expressed as percentage of the total mass $\left(m_{\mathrm{tot}}\right)$.

\section{Layout and simulated design of the base-isolated retrofitted structures}

To retrofit the six-storey original (fixed-base) framed building, for attaining performance levels imposed by the

Table 1 Floor masses and cross section $(\mathrm{cm} \times \mathrm{cm})$ of girders for the original fixed-base structure

\begin{tabular}{llll}
\hline Floor level & $m_{i}\left(\mathrm{kNs}^{2} / \mathrm{m}\right)$ & Deep & Flat \\
\hline 1 & 328.17 & $40 \times 70$ & $60 \times 25$ \\
2 & 308.25 & $40 \times 60$ & $60 \times 25$ \\
3 & 280.20 & $30 \times 55$ & $50 \times 25$ \\
4 & 272.17 & $30 \times 50$ & $50 \times 25$ \\
5 & 258.57 & $30 \times 45$ & $40 \times 25$ \\
6 & 186.49 & $30 \times 45$ & $40 \times 25$ \\
\hline
\end{tabular}

Table 2 Cross section $(\mathrm{cm} \times \mathrm{cm})$ of columns for the original fixedbase structure

\begin{tabular}{llll}
\hline Storey & Corner & Perimeter & Interior \\
\hline 1 & $30 \times 50$ & $30 \times 60$ & $60 \times 60$ \\
2 & $30 \times 50$ & $30 \times 60$ & $60 \times 60$ \\
3 & $30 \times 40$ & $30 \times 50$ & $50 \times 50$ \\
4 & $30 \times 40$ & $30 \times 50$ & $50 \times 50$ \\
5 & $30 \times 35$ & $30 \times 40$ & $40 \times 40$ \\
6 & $30 \times 30$ & $30 \times 30$ & $30 \times 30$ \\
\hline
\end{tabular}

Table 3 Dynamic properties of the original fixed-base structure $\left(m_{\text {tot }}=1634 \mathrm{kNs}^{2} / \mathrm{m}\right)$

\begin{tabular}{llll}
\hline Mode & $T_{i}(\mathrm{~s})$ & $m_{\mathrm{E}, X}\left[\% m_{\mathrm{tot}}\right]$ & $m_{\mathrm{E}, Y}\left[\% m_{\mathrm{tot}}\right]$ \\
\hline 1 & 0.743 & 79 & - \\
2 & 0.665 & - & 76 \\
3 & 0.290 & 13 & - \\
4 & 0.269 & - & 15 \\
5 & 0.178 & 4.4 & - \\
6 & 0.166 & - & 5.3 \\
\hline
\end{tabular}

current Italian code (NTC08) in a high-risk seismic zone (peak ground acceleration on rock, $a_{\mathrm{g}}=0.262 \mathrm{~g}$ at the lifesafety limit state) and medium subsoil class (class $\mathrm{C}$, site amplification factor, $S=1.319$ ), three in-plan configurations of elastomeric and sliding bearings are considered: (a) EBI structure in Fig. 6, with elastomeric bearings acting alone (i.e. high-damping-laminated-rubber bearings, HDLRBs type 1); (b) ESBI structure in Fig. 7, with an inparallel combination of elastomeric (i.e. HDLRBs type 2) and friction (i.e. steel-PTFE sliding bearings, SBs) bearings; (c) EFBI structure in Fig. 8, with friction pendulum bearings (i.e. FPBs) acting alone. An additional mass of

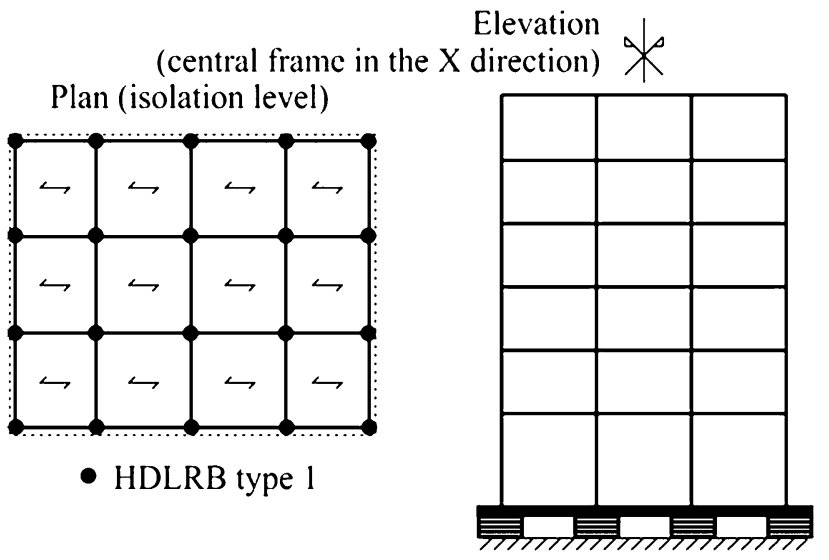

Fig. 6 EBI structure: HDLRBs type 1 acting alone 


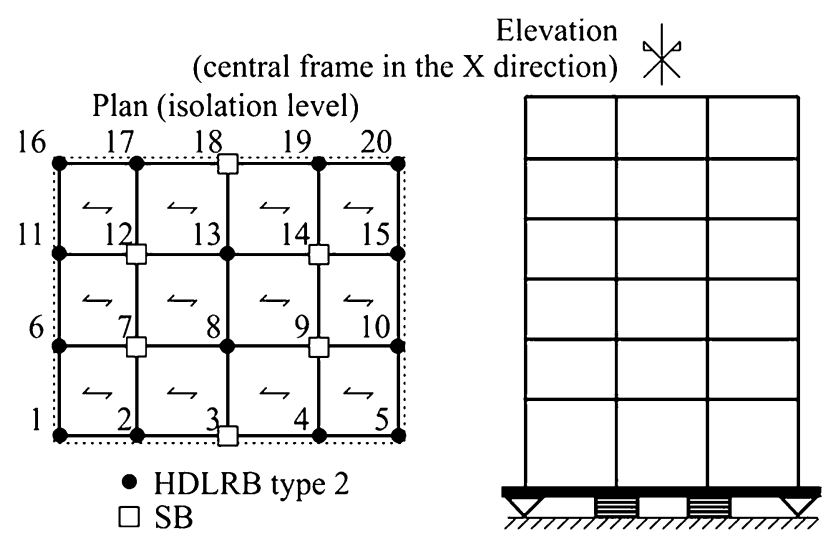

Fig. 7 ESBI structure: in-parallel combination of HDLRBs type 2 and SBs

$511 \mathrm{kNs}^{2} / \mathrm{m}$, placed above the isolation level, is assumed at the level of the rigid girders, with a cross section of $50 \times 100 \mathrm{~cm}^{2}$. The base isolation systems are designed assuming the same values of the fundamental vibration period (i.e. $T_{l \mathrm{H}}=2.5 \mathrm{~s}$ ), considering the fundamental vibration periods of the fixed-base structure reported in Table 3 (modes 1 and 2), and equivalent viscous damping ratio (i.e. $\xi_{\mathrm{H}}=18 \%$ ). Finally, the (horizontal) design spectral displacement at the NTC08 collapse limit state is assumed equal to $23.33 \mathrm{~cm}$.

\subsection{EBI structure}

The design of the twenty HDLRBs type 1 of the EBI structure shown in Fig. 6, which are simply assumed with the same dimensions so as to obtain a larger torsional stiffness, is carried out according to the prescriptions imposed by NTC08 at the collapse limit state. A shear modulus $G=0.4 \mathrm{MPa}$ and a volumetric compression modulus $E_{\mathrm{b}}=2000 \mathrm{MPa}$ are assumed for the elastomer.

The HDLRBs fulfil the ultimate limit state (ULS) verifications regarding the maximum shear strains: i.e. $\gamma_{\text {tot }}=\gamma_{\mathrm{s}}+\gamma_{\mathrm{c}}+\gamma_{\alpha} \leq 5$ and $\gamma_{\mathrm{s}} \leq 2$, where $\gamma_{\text {tot }}$ represents the total design shear strain, while $\gamma_{s}, \gamma_{c}$ and $\gamma_{\alpha}$ represent the shear strains of the elastomer due to seismic displacement, axial compression and angular rotation, respectively. Moreover, the maximum compression axial load $(P)$ does not exceed the critical load $\left(P_{\mathrm{cr}}\right)$ divided by a safety coefficient equal to 2.0. The minimum tensile stress $\left(\sigma_{t}\right)$ resulting from the seismic analysis is assumed as $2 G(=0.8 \mathrm{MPa})$. A nominal stiffness ratio $\alpha_{\mathrm{K} 0}$, defined as the ratio between the nominal value of the vertical stiffness $\left(K_{\mathrm{V} 0}\right)$ and the analogous value of the horizontal stiffness $\left(K_{\mathrm{H} 0}\right)$, equal to 1200 is assumed for the isolators. In Table 4, initial stiffnesses and equivalent damping coefficients corresponding to viscous damping ratios of $18 \%$ and $5 \%$ in the horizontal (i.e. $C_{\mathrm{H}}$ ) and vertical (i.e. $C_{\mathrm{V}}$ )
Table 4 Dynamic properties of the HDLRBs

\begin{tabular}{lllllll}
\hline$\alpha_{\mathrm{K} 0}$ & $\xi_{\mathrm{H}}$ & $\xi_{\mathrm{V}}$ & $K_{\mathrm{H} 0}$ & $K_{\mathrm{V} 0}$ & $C_{\mathrm{H}}$ & $C_{\mathrm{V}}$ \\
\hline 1200 & $18 \%$ & $5 \%$ & 6.77 & 8129 & 0.97 & 9.31 \\
\hline
\end{tabular}

directions, respectively, are reported. The following geometrical and mechanical properties of the HDLRBs type 1 are reported in Table 5: the diameter of the steel layer $\left(D_{\mathrm{s}}\right)$ and that of the elastomer $\left(D_{\mathrm{e}}\right)$; the total thickness of elastomer $\left(t_{\mathrm{e}}\right)$; primary $\left(S_{1}\right)$ and secondary $\left(S_{2}\right)$ shape factors; compression modulus of the elastomer $\left(E_{\mathrm{c}}\right)$. Finally, in Table 6 results of the ULS verifications for the HDLRBs are shown. It is worth noting that the buckling control proved to be the more restrictive while no tensile axial loads were found.

\subsection{EFBI structure}

The design of the in-parallel combination of fourteen HDLRBs type 2 and six steel-PTFE SBs for the ESBI structure shown in Fig. 7 is carried out in order to increase the secondary shape factor of the elastomeric bearings (e.g. $S_{2} \geq 4$ is a conservative assumption against buckling) in comparison with HDLRBs type 1 shown in Table 5. To this end, a value equal to 0.38 is assumed for the nominal sliding ratio $\alpha_{\mathrm{S} 0}\left(=F_{\mathrm{S} 0} / F_{\mathrm{S} 0 \text {, max }}\right)$ of the SBs under gravity loads, defined as the global sliding force $\left(F_{\mathrm{S} 0}\right)$ divided by the maximum sliding force $\left(F_{\mathrm{S} 0 \text {, max }}\right)$; this latter one evaluated supposing that sliding bearings are placed under each column. The same nominal stiffness ratio adopted for the EBI structure (i.e. $\alpha_{\mathrm{K} 0}=1200$ ) is assumed in this case for the HDLRBs type 2.

An equivalent viscous damping of the sliding bearings $\left(\xi_{\mathrm{H}, \mathrm{SBs}}\right)$ equal to $5 \%$ is calculated in accordance with Eqs. (5a)-(5e), referring to the (horizontal) spectral displacement at the collapse limit state (i.e. $S_{\mathrm{d}}=23.33 \mathrm{~cm}$ ) and considering the gravity loads and a dynamic-fast sliding friction coefficient $\mu_{\max }=4.2 \%$. Finally, the equivalent viscous damping ratios of the HDLRBs type 2 are assumed equal to $\xi_{\mathrm{H}, \mathrm{HDLRBs}}=13 \%$ and $\xi_{\mathrm{V}}=5 \%$ in the horizontal and vertical directions, respectively. Main properties of the HDLRBs are reported in Tables 7, 8 and 9. It is noteworthy that the design of the elastomeric bearings has been limited by the condition imposed on the maximum total shear strain (i.e. see $\gamma_{\text {tot }}$ in Table 9). Dynamic properties of the SBs are also reported in Table 10, where $P_{\text {sd }}$ is the compression axial load under quasi-permanent gravity loads. The nonlinear dynamic analysis will be carried out assuming $\mu_{\max } / \mu_{\min }=2.5$ and a rate parameter $\alpha$ [see Eq. (4b)] equal to $5.5 \mathrm{~m} / \mathrm{s}$, according to experimental results (Cardone et al. 2015). 
Table 5 Geometric properties of the HDLRBs

\begin{tabular}{llllll}
\hline$D_{\mathrm{s}}(\mathrm{cm})$ & $D_{\mathrm{e}}(\mathrm{cm})$ & $t_{\mathrm{e}}(\mathrm{cm})$ & $S_{1}$ & $S_{2}$ & $E_{\mathrm{c}}\left(\mathrm{kN} / \mathrm{cm}^{2}\right)$ \\
\hline 60.00 & 63.00 & 18.66 & 18.71 & 3.21 & 53.86 \\
\hline
\end{tabular}

Table 6 Results of ULS verifications for the HDLRBs

\begin{tabular}{llll}
\hline$\gamma_{\mathrm{s}}$ & $\gamma_{\text {tot, } \max }$ & $\left(P_{\mathrm{cr}} / P\right)_{\min }$ & $\left(\sigma_{\mathrm{t}} / \sigma_{\mathrm{tu}}\right)_{\max }$ \\
\hline 1.25 & 3.67 & 2.00 & 0 \\
\hline
\end{tabular}

Table 7 Dynamic properties of the HDLRBs

\begin{tabular}{lllllll}
\hline$\alpha_{\mathrm{K} 0}$ & $\xi_{\mathrm{H}, \mathrm{HDLRBs}}$ & $\xi_{\mathrm{V}}$ & $K_{\mathrm{H} 0}$ & $K_{\mathrm{V} 0}$ & $C_{\mathrm{H}}$ & $C_{\mathrm{V}}$ \\
\hline 1200 & $13 \%$ & $5 \%$ & 8.66 & 10396 & 1.0 & 12.58 \\
\hline
\end{tabular}

Table 8 Geometric properties of the HDLRBs

\begin{tabular}{llllll}
\hline$D_{\mathrm{s}}(\mathrm{cm})$ & $D_{\mathrm{e}}(\mathrm{cm})$ & $t_{\mathrm{e}}(\mathrm{cm})$ & $S_{1}$ & $S_{2}$ & $E_{\mathrm{c}}\left(\mathrm{kN} / \mathrm{cm}^{2}\right)$ \\
\hline 56.00 & 57.00 & 11.84 & 17.57 & 4.75 & 49.58 \\
\hline
\end{tabular}

Table 9 Results of the ULS verifications for the HDLRBs

\begin{tabular}{llll}
\hline$\gamma_{\mathrm{s}}$ & $\gamma_{\mathrm{tot}, \max }$ & $\left(P_{\mathrm{cr}} / P\right)_{\min }$ & $\left(\sigma_{\mathrm{t}} / \sigma_{\mathrm{tu}}\right)_{\max }$ \\
\hline 1.97 & 5.00 & 2.37 & 0 \\
\hline
\end{tabular}

\subsection{FPBI structure}

The alternative of using twenty FPBs acting alone (i.e. $\alpha_{\mathrm{S} 0}=1.0$ ), which are simply assumed with the same effective radius of curvature $(R)$ of the sliding interface, is also taken into account in the design of the FPBI structure shown in Fig. 8, assuming the same friction coefficients of the steel-PTFE SBs considered in the ESBI structure (i.e. $\mu_{\min }=1.68 \%$ and $\mu_{\max }=4.2 \%$ ).

The in-plan configuration of the FPBs consists of the six types reported in Table 11, according to their maximum axial load capacity $\left(P_{\mathrm{Ed}}\right)$ and quasi-permanent gravity load $\left(P_{\text {sd }}\right)$ evaluated in the FPBI structure. To this end, the experimental law derived by a leading world manufacturer of FPS (FIP Industriale 2013) is assumed, to take into account the law of variability of the dynamic-fast friction coefficient with the compression axial load [i.e. see $\mu_{\max }$ in Eq. (4b)]:

$\mu_{\max }=2.5\left(\frac{P_{\mathrm{sd}}}{P_{\mathrm{Ed}}}\right)^{-0.834}$
Table 10 Dynamic properties of the SBs

\begin{tabular}{llllll}
\hline $\mathrm{SB}$ & $\xi_{\mathrm{H}, \mathrm{SBs}}(\%)$ & $\mu_{\min }(\%)$ & $\mu_{\max }(\%)$ & $\alpha(\mathrm{m} / \mathrm{s})$ & $P_{\mathrm{sd}}(\mathrm{kN})$ \\
\hline 3,18 & 5 & 1.68 & 4.2 & 5.5 & 1029 \\
$7,9,12,14$ & 5 & 1.68 & 4.2 & 5.5 & 1458 \\
\hline
\end{tabular}

Table 11 Dynamic properties of the FPs

\begin{tabular}{lllcc}
\hline FP & $\xi_{\mathrm{H}}(\%)$ & $R(\mathrm{~cm})$ & $P_{\mathrm{sd}}(\mathrm{kN})$ & $P_{\mathrm{Ed}}(\mathrm{kN})$ \\
\hline $1,5,16,20$ & 18 & 216 & 515 & 973 \\
$2,4,17,19$ & 18 & 216 & 974 & 1840 \\
3,18 & 18 & 216 & 1029 & 1943 \\
$6,10,11,15$ & 18 & 216 & 1020 & 1926 \\
$7,9,12,14$ & 18 & 216 & 1458 & 2754 \\
8,13 & 18 & 216 & 1547 & 2922 \\
\hline
\end{tabular}

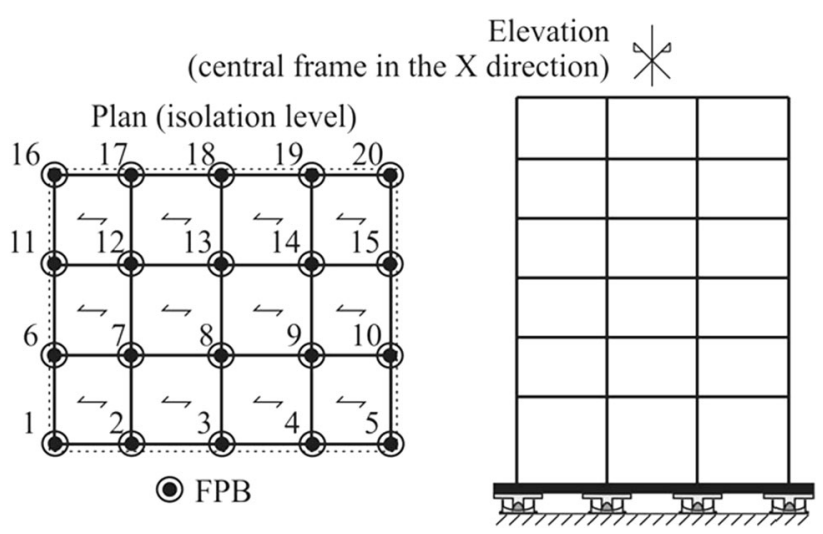

Fig. 8 FPBI structure: FPBs acting alone

with reference to low-type friction characteristic. Thus, the nominal axial load ratio $\alpha_{\mathrm{P} 0}\left(=P_{\mathrm{sd}} / P_{\mathrm{Ed}}\right)$ is assumed constant and equal to 0.529 for all the FPBs.

\section{Numerical results}

To study the nonlinear dynamic response of the (original) fixed-base and (retrofitted) base-isolated structures above described, near-fault ground motions are considered. Longduration horizontal pulses due to forward-directivity and fling-step effects characterise these motions (Mazza and Vulcano 2009, 2012; Mazza 2015a, b, c). In particular, earthquake rupture towards a site tends to produce a shortduration, but large amplitude, two-sided velocity pulses principally in the horizontal direction normal to the fault strike; on the other hand, fling-step is associated with the permanent displacement that occurs across a ruptured fault and, generally, presents one-sided velocity pulses in the slip 
Table 12 Main data of the near-fault ground motions

\begin{tabular}{lllllllr}
\hline Country & Component & Station & $M_{\mathrm{w}}$ & $\Delta(\mathrm{km})$ & $P G A_{\mathrm{H}}(\mathrm{g})$ & Pulse-type & $T_{\mathrm{p}}(\mathrm{s})$ \\
\hline Iran & TR & Tabas & 7.7 & 3 & 0.852 & Forward-directivity & 6.19 \\
USA & 225 & Parachute & 6.4 & 0.7 & 0.455 & Forward-directivity & 2.39 \\
USA & 000 & Gilroy\#3 & 7.0 & 6.3 & 0.544 & Forward-directivity & 1.16 \\
USA & 046 & Newhall & 6.7 & 7.1 & 0.446 & Forward-directivity & 1.25 \\
Japan & 090 & Takatori & 6.9 & 4.3 & 0.616 & Forward-directivity & 1.55 \\
Turkey & 270 & Duzce & 7.4 & 11 & 0.351 & Forward-directivity & 5.94 \\
Taiwan & EW & TCU068 & 7.3 & 3 & 0.566 & Fling-step & 12.29 \\
\hline
\end{tabular}

Table 13 Scale factors of the near-fault ground motions

\begin{tabular}{llll}
\hline EQ & Station & $S_{\mathrm{FFB}}$ & $S_{\mathrm{FBI}}$ \\
\hline Tabas 1978 & Tabas & 0.446 & 0.470 \\
Superstition Hills 1987 & Parachute & 0.796 & 0.286 \\
Loma Prieta 1989 & Gilroy\#3 & 1.342 & 1.952 \\
Northridge 1994 & Newhall & 0.814 & 0.609 \\
Kobe 1995 & Takatori & 0.519 & 0.293 \\
Kocaeli 1999 & Duzce & 1.025 & 0.718 \\
Chi-Chi (Ji-Ji) 1999 & TCU068 & 0.715 & 0.450 \\
\hline
\end{tabular}

parallel direction. Seven near-fault ground motions available in the Pacific Earthquake Engineering Research Center Database (Pacific Earthquake Engineering Research Center 2008) are selected, based on the design hypotheses adopted for the test structure (i.e. subsoil class $\mathrm{C}$ and high-risk seismic region). For each ground motion, attention is focused on the component with forward-directivity effects. The main data of the near-fault earthquakes (EQs) are shown in Tables 12 and 13, i.e., country, station, year, component, magnitude $\left(M_{\mathrm{w}}\right)$, epicentral distance $(\Delta)$, peak ground acceleration $\left(\mathrm{PGA}_{\mathrm{H}}\right)$, pulse-type and period of the velocity pulse. Moreover, different scale factors are considered for the normalization of the near-fault EQs with respect to NTC08 acceleration design spectrum, in accordance with the elastic spectral acceleration at the fundamental vibration period of the fixed-base $\left(S_{\mathrm{FFB}}\right)$ and base-isolated $\left(S_{\mathrm{FBI}}\right)$ structures. The elastic response spectra of acceleration $\left(S_{\mathrm{a}} / \mathrm{g}\right)$ are plotted in Fig. 9, assuming an equivalent viscous damping ratio in the horizontal direction $\left(\xi_{\mathrm{H}}\right)$ equal to $18 \%$. Note that the mean spectrum of the near-fault EQs, normalised with the scale factors $S_{\mathrm{FBI}}$, matches the corresponding target response spectrum of NTC08 for vibration periods greater than the fundamental vibration period of the base-isolated structures (i.e. $T_{1 \mathrm{H}}=2.5 \mathrm{~s}$ ). All the following results are obtained as an average of those separately obtained for these ground motions.

At each step of the analysis, plastic conditions are checked at the potential critical sections of the girders and columns using a bilinear model with a hardening

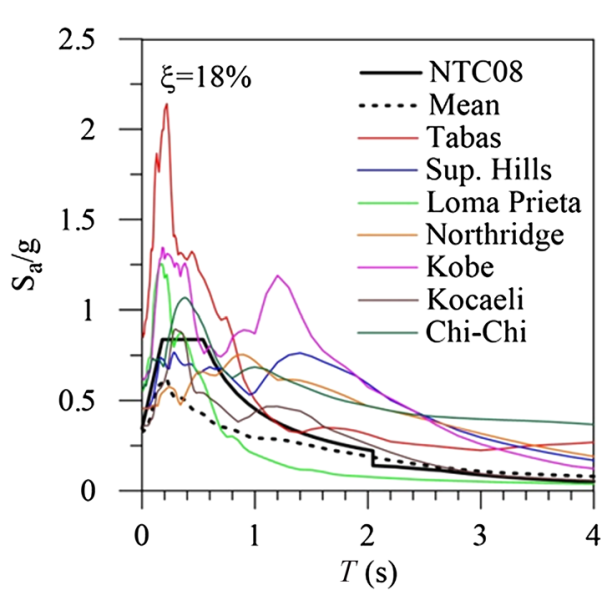

Fig. 9 Acceleration (elastic) response spectra

ratio of $5 \%$ (Mazza and Vulcano 2010; Mazza 2014b, c). The effect of the axial load on the ultimate bending moment of the columns is also considered. The local damage undergone by r.c. frame members is evaluated considering the ductility demand calculated in terms of curvature. In particular, maximum values of the curvature ductility demand for the potentially critical sections of the girders (i.e. end, quarter span and mid-span girder sections) are evaluated for each of the two loading directions. Moreover, for the columns the ductility demand is evaluated with reference to the radial direction, because it is sensitive to the direction of the bending moment axis vector which changes at each step of the loading history:

$\mu_{\chi, \max }=\frac{\chi_{\max , r}}{\chi_{\mathrm{E} r}}=\frac{\sqrt{\left(\chi_{\mathrm{E} y}+\sum \Delta \chi_{\mathrm{Py}}\right)^{2}+\left(\chi_{\mathrm{E} z}+\sum \Delta \chi_{\mathrm{P} z}\right)^{2}}}{\frac{M_{\mathrm{Pr}}\left[N_{\mathrm{V}}\right]}{E I_{\mathrm{r}}}}$

where $\chi_{\text {max,r }}$ and $\chi_{\mathrm{E}, \mathrm{r}}$ represent maximum and yielding curvatures, respectively, in the radial direction. At each step of the analysis, plastic curvatures (i.e. $\Delta \chi_{\mathrm{P} y}$ and $\Delta \chi_{\mathrm{P} z}$ ) are accumulated and added to the yielding curvatures at the 


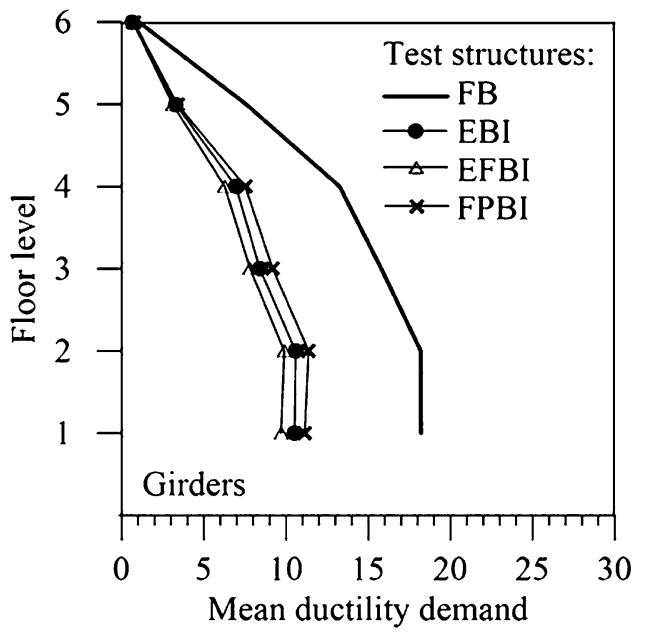

(a)

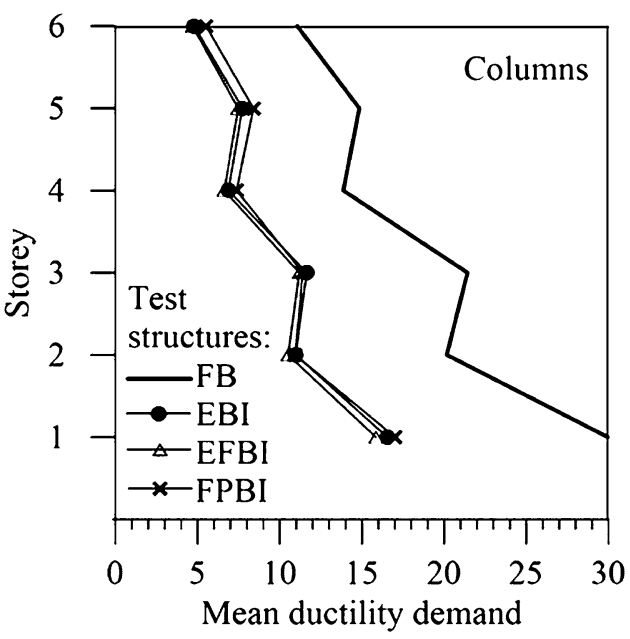

(b)

Fig. 10 Comparison of ductility demands for r.c. frame members of the fixed-base and base-isolated structures

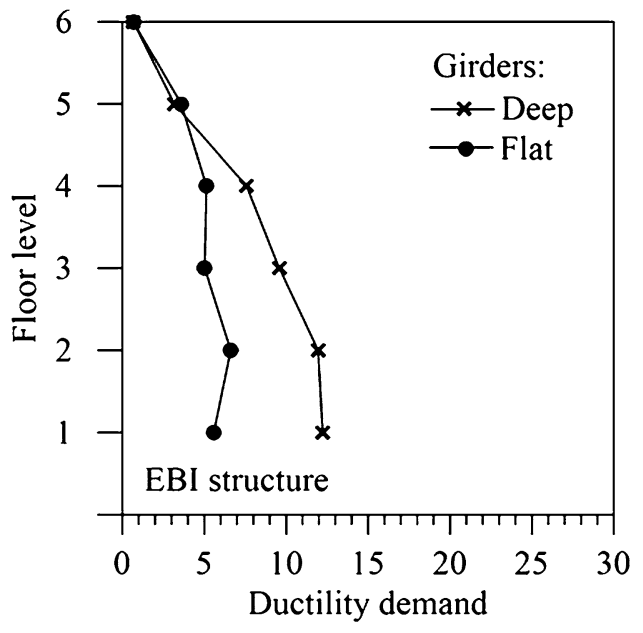

(a)

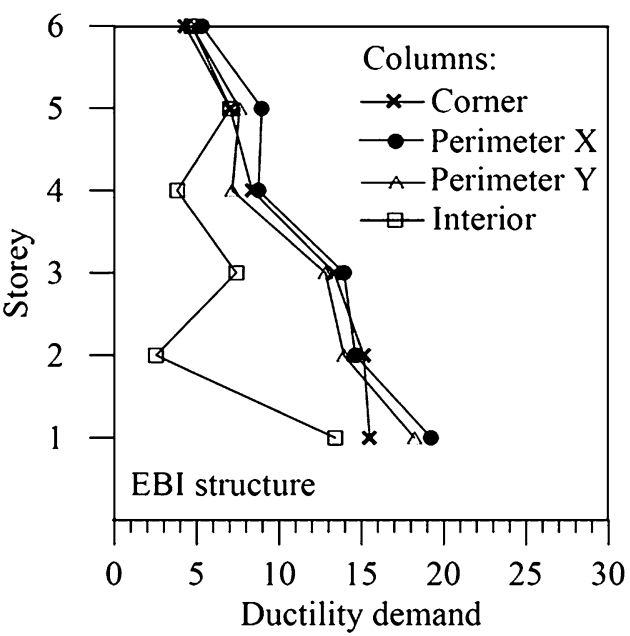

(b)

Fig. 11 Ductility demand of r.c. frame members for the HDLRBs acting alone

current step (i.e. $\chi_{\mathrm{E} y}$ and $\chi_{\mathrm{E} z}$ ). Finally, the plastic moment $M_{\text {Pr }}$ is calculated considering the axial force due to the gravity loads only $\left(N_{\mathrm{V}}\right)$ and referring to the radial direction identified by $\chi_{\max , \mathrm{r}}$.

The ultimate values of the total shear strain $\left(\gamma_{\text {tot, }}\right)$ and the corresponding shear strain due to seismic displacement $\left(\gamma_{\mathrm{s}, \mathrm{u}}\right)$ of the HDLRBs are assumed equal to $7.5(=1.5 \times 5)$ and $3(=1.5 \times 2)$, respectively (i.e. 1.5 times the design values); moreover, the compressive and tensile axial loads of the HDLRBs are limited, respectively, to the critical buckling load $\left(P_{\text {cr }}\right)$, evaluated according to Eq. (2a), and the tensile value $\left(P_{\mathrm{tu}}\right)$, obtained multiplying the reduced effective area by a limit stress tension $\left(\sigma_{\mathrm{tu}}\right)$ equal to $0.8 \mathrm{MPa}$. The friction coefficient of the SBs and FPBs is evaluated according to Eq. (4b), for mean values of contact pressure and temperature, assuming $\mu_{\min }=1.68 \%$, $\mu_{\max }=4.2 \%$ and $\alpha=5.5 \mathrm{~s} / \mathrm{m}$.

Firstly, a comparison of the mean of maximum ductility demand obtained for the (original) fixed-base and (retrofitted) base-isolated structures (i.e. the EBI, FBI and FPBI structures) is shown in Fig. 10, along the building height. As shown, all the base isolation systems were effective for reducing global floor damage of girders (Fig. 10a) and columns (Fig. 10b), producing similar behaviour of the superstructure.

Then, in order to investigate the effects due to the horizontal components of the near-fault EQs on the local damage of r.c. frame members, results obtained for the EBI (Fig. 11), EFBI (Fig. 12) and FPBI (Fig. 13) base-isolated structures are investigated separately. To this end, mean of maximum ductility demand of deep and flat girders 


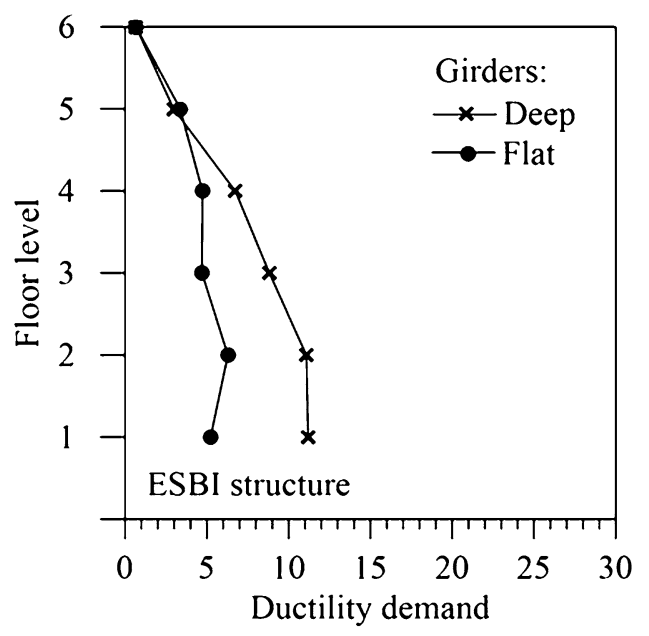

(a)

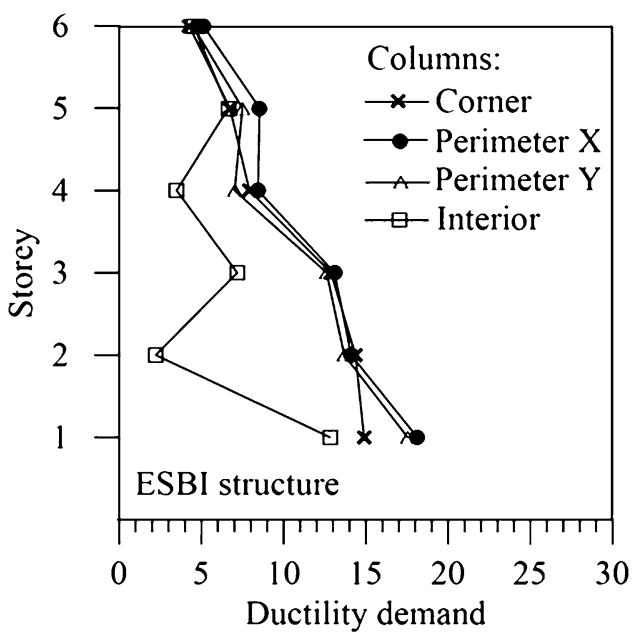

(b)

Fig. 12 Ductility demand of r.c. frame members for the in-parallel combination of HDLRBs and SBs

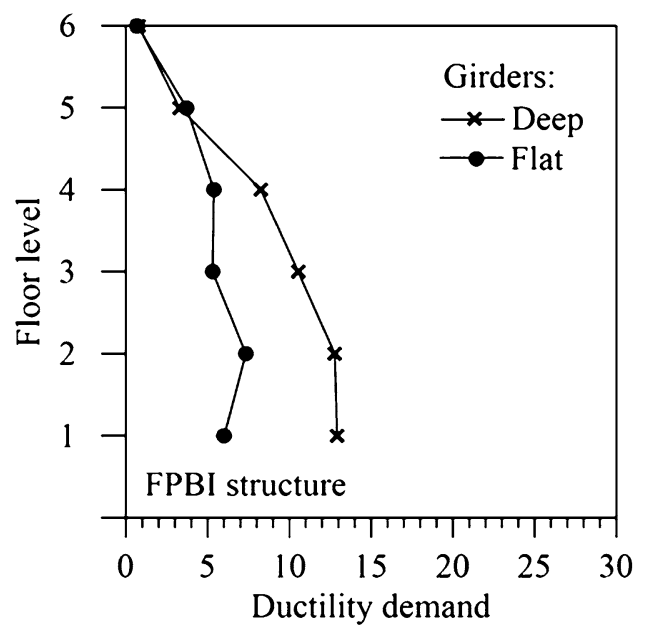

(a)

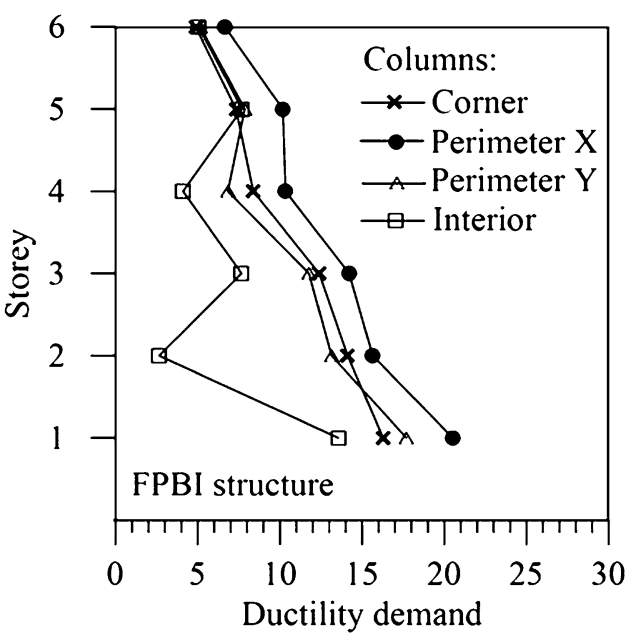

(b)

Fig. 13 Ductility demand of r.c. frame members for the FPBs acting alone

(Figs. 10a, 11a, 12a) as well as corner, perimeter (in the $X$ and $Y$ directions) and central columns (Figs. 10b, 11b, 12b) are plotted along the building height. It is worth noting that only the nonlinear dynamic analysis of the EFBI structure under the Chi-Chi (Ji-Ji) EQ has been stopped at the time when the maximum value imposed on the total shear strain of the HDLRBs is exceeded. This kind of behaviour can be interpreted as an amplification of the response during the fling-step Chi-Chi (Ji-Ji) EQ due to the long duration of the pulse velocity (see Table 12).

As can be observed, for all the base isolation systems unexpected high ductility demands are induced at the lower floors, especially in deep girders and in perimeter and interior columns. This behaviour is more evident for the
FPBI structure, whose response in the horizontal direction is like that of a fixed-base structure until the friction threshold imposed by the FPBs is not exceeded. A similar behaviour is obtained for the EBI and EFBI structures.

Afterwards, the attention is focused on the nonlinear dynamic response of HDLRBs of the EBI (i.e. type 1) and EFBI (i.e. type 2) structures, by evaluating maximum values of the seismic shear strain (i.e. $\gamma_{\mathrm{s}}$ in Figs. 14a, 15a) and total shear strain (i.e. $\gamma_{\text {tot }}$ in Figs. $14 \mathrm{~b}, 15 \mathrm{~b}$ ) separately obtained for each near-fault EQ. The corresponding NTC08 thresholds are also shown with dotted lines.

It is interesting to note that the EFBI structure is characterised by maximum values of $\gamma_{\mathrm{s}}$ greater than those obtained for the EBI structure and its failure occurred 


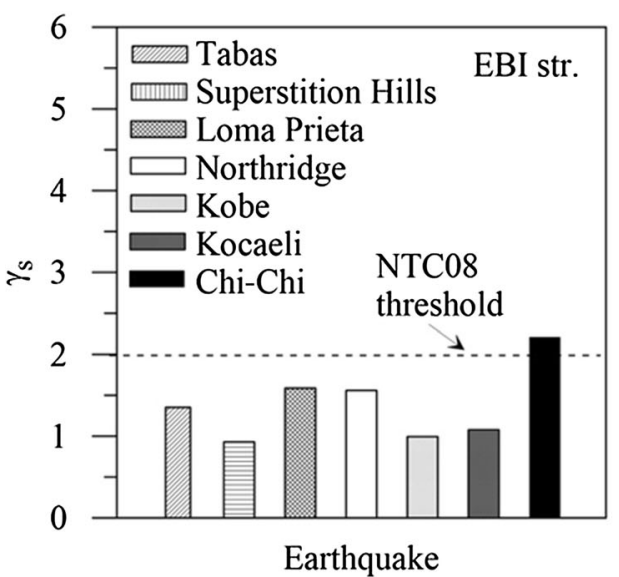

(a)

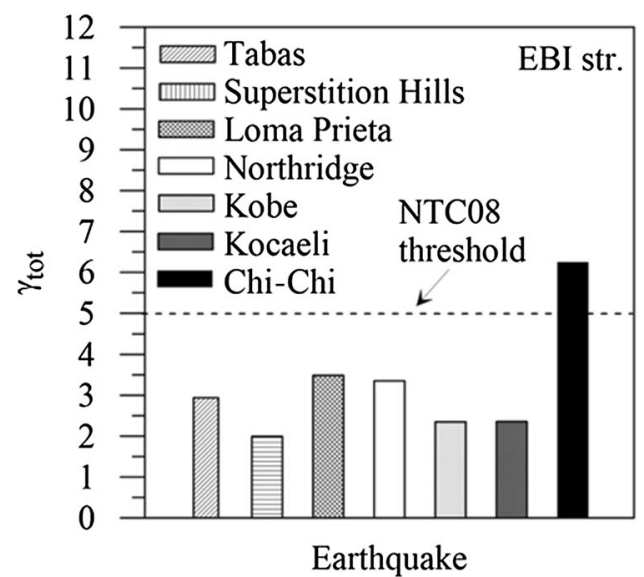

(b)

Fig. 14 Maximum shear strains of the HDLRBs for the EBI structure

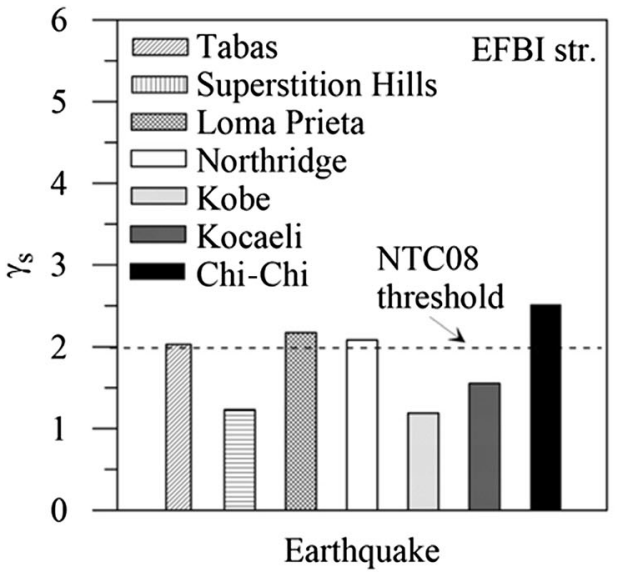

(a)

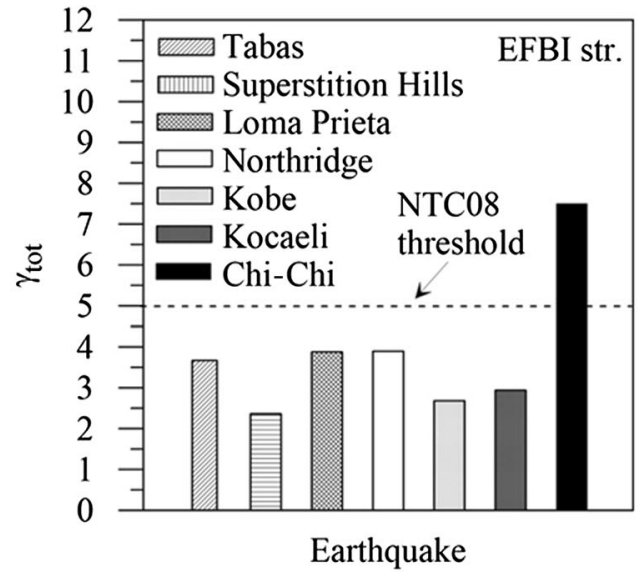

(b)

Fig. 15 Maximum shear strains of the HDLRBs for the EFBI structure

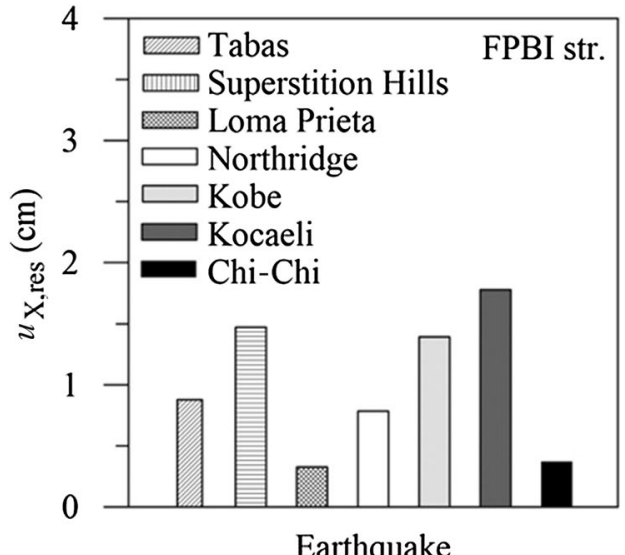

(a)

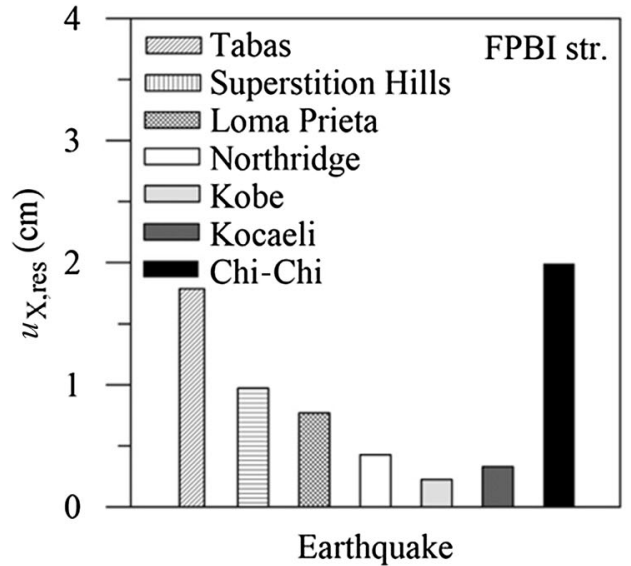

(b)

Fig. 16 Maximum residual displacement for the FPBs of the FPBI structure 
before the end of the Chi-Chi ( $\mathrm{Ji}-\mathrm{Ji})$ EQ because the ultimate value of $\gamma_{\text {tot }}(=7.5)$ exceeded (Fig. 15b). This behaviour can be interpreted observing that the height of the HDLRBs type 2 (Table 8) is about $2 / 3$ of that corresponding to the HDLRBs type 1 (Table 5).

Finally, maximum residual displacement of the FPBI structure, along the in-plan $X$ (i.e. $u_{X, \text { res }}$ in Fig. 16a) and $Y\left(u_{Y, \text { res }}\right.$ in Fig. 16b) principal directions, have highlighted re-centring problems of the FPBs under near-fault EQs. Further results, omitted for the sake of brevity, confirm sufficient restoring capability of the EFBI structure.

\section{Conclusions}

The nonlinear dynamic response of a six-storey framed building which, primarily designed (as to be a fixed-base one) in compliance with the previous Italian code for a medium-risk seismic zone, has to be retrofitted with a base isolation system for attaining performance levels imposed by the current Italian code in a high-risk seismic zone, has been studied under near-fault EQs.

Besides the fixed-base original structure, three cases of base isolation are examined: HDLRBs acting alone (i.e. the EBI structure); in-parallel combination of HDLRBs and SBs (i.e. the EFBI structure); FPBs acting alone (i.e. the FPBI structure). Elastic spectral acceleration at the fundamental vibration period of the original and retrofitted structures are considered to normalise the near-fault ground motions with respect to the NTC08 acceleration design spectrum.

As expected, all the base isolation systems are effective for reducing local damage of r.c. frame members, in comparison with the (original) fixed-base structure. However, unexpected high values of ductility demand are resulted especially at the lower floors, at the end sections of deep girders and of perimeter and interior columns. This behaviour is more evident for the FPBI structure, whose response in the horizontal direction is like that of a fixedbase structure until the friction threshold imposed by the FPBs is not exceeded.

Failure of the isolation system can be induced by the attainment of the limit value imposed on the total shear strain and the corresponding shear strain due to seismic displacement, especially for the HDLRBs of the EFBI structure. Finally, re-centring problems of the FPBs have highlighted under near-fault EQs, while sufficient restoring capability is obtained for the EFBI structure.

Acknowledgments The present work was partially financed by Re.L.U.I.S. (Italian network of university laboratories of earthquake engineering), under the project "Convenzione D.P.C.-Re.L.U.I.S. 2014-2016, WPI, Isolation and Dissipation".
Open Access This article is distributed under the terms of the Creative Commons Attribution 4.0 International License (http://crea tivecommons.org/licenses/by/4.0/), which permits unrestricted use, distribution, and reproduction in any medium, provided you give appropriate credit to the original author(s) and the source, provide a link to the Creative Commons license, and indicate if changes were made.

\section{References}

Baratta A, Corbi I, Corbi O, Mastorakis N (2015) Strategies for the protection from structural failures under seismic events. Int $\mathbf{J}$ Mech 9:69-76

Braga F, Faggella M, Gigliotti R, Laterza M (2005) Nonlinear dynamic response of HDRB and hybrid HDRB-friction sliders base isolation systems. Bull Earthq Eng 3:333-353

Cardone D, Gesualdi G, Brancato P (2015) Restoring capability of friction pendulum seismic isolation systems. Bull Earthq Eng 13(8):2449-2480

Christopoulos C, Filiatrault A (2006) Principles of passive supplemental damping and seismic isolation. IUSS Press, Istituto Universitario di Studi Superiori di Pavia (Italy), Pavia

Corbi O, De Barros RC (2013) Seismic protection of civil buildings by visco-elastic magneto-rheological fluids. Int $\mathrm{J}$ Mech 7(4):518-525

Corbi O, Zaghw AH (2013) Properties and design of dissipative viscorecentring SMA members for civil structures. Int J Mech 7(3):285-292

Dolce M, Cardone D, Croatto F (2005) Frictional behaviour of steelPTFE interfaces for seismic isolation. Bull Earthq Eng 3:75-99

FIP Industriale (2013) Catalogue S04. Curved surface sliders, Padova, Italy. http://www.fipindustriale.it

Gur S, Mishra SK, Chakraborty S (2013) Performance assessment of building isolated by shape-memory-alloy-rubber-bearing (SMARB) and conventional elastomeric bearing under nearfault earthquakes. J Control Health Monitor 21(4):449-465

Kasalanati A, Constantinou MC (2005) Testing and modeling of prestressed isolators. J Struct Eng 131:857-866

Mazza F (2014a) A distributed plasticity model to simulate the biaxial behaviour in the nonlinear analysis of spatial framed structures. Comput Struct 135:141-154

Mazza F (2014b) Displacement-based seismic design of hysteretic damped braces for retrofitting in-plan irregular r.c. framed structures. Soil Dyn Earthq Eng 66:231-240

Mazza F (2014c) Modeling and nonlinear static analysis of reinforced concrete framed buildings irregular in plan. Eng Struct 80:98-108

Mazza F (2015a) Comparative study of the seismic response of RC framed buildings retrofitted using modern techniques. Earthq Struct 9(1):29-48

Mazza F (2015b) Nonlinear incremental analysis of fire-damaged r.c. base-isolated structures subjected to near-fault ground motions. Soil Dyn Earthq Eng 77:192-202

Mazza F (2015c) Seismic vulnerability and retrofitting by damped braces of fire-damaged r.c. framed buildings. Eng Struct 101:179-192

Mazza F, Vulcano A (2007) Control of the along-wind response of steel framed buildings by using viscoelastic or friction dampers. Wind Struct 10(3):233-247

Mazza F, Vulcano A (2009) Nonlinear response of rc framed buildings with isolation and supplemental damping at the base subjected to near-fault earthquakes. J Earthq Eng 13(5):690-715 
Mazza F, Vulcano A (2010) Nonlinear dynamic response of r.c. framed structures subjected to near-fault ground motions. Bull Earthq Eng 8:1331-1350

Mazza F, Vulcano A (2011) Control of the earthquake and wind dynamic response of steel-framed buildings by using additional braces and/or viscoelastic dampers. Earthq Eng Struct Dyn 40(2):155-174

Mazza F, Vulcano A (2012) Effects of near-fault ground motions on the nonlinear dynamic response of base-isolated r.c. framed buildings. Earthq Eng Struct Dyn 41:211-232

Mazza F, Vulcano A (2013) Nonlinear seismic analysis to evaluate the effectiveness of damped braces. Int J Mech 7(3):251-261

Mazza F, Vulcano A (2014a) Design of hysteretic damped braces to improve the seismic performance of steel and RC framed structures. Ingegneria Sismica 31(1):1-12

Mazza F, Vulcano A (2014b) Displacement-based design procedure of damped braces for the seismic retrofitting of r.c. framed buildings. Bull Earthq Eng 13(7):2121-2143

Mazza F, Vulcano A (2014c) Equivalent viscous damping for displacement-based seismic design of hysteretic damped braces for retrofitting framed buildings. Bull Earthq Eng 12(6): $2797-2819$
Naeim F, Kelly JM (1999) Design of seismic isolated structures: from theory to practice. Wiley, New York

Ozbulut OE, Hurlebaus S (2011) Optimal design of superelasticfriction base isolator for seismic protection of highway bridges against near-fault earthquakes. Earthq Eng Struct Dyn 40:273-291

Pacific Earthquake Engineering Research center (2008) Next generation attenuation (NGA) database. http://peer.berkeley.edu/peer ground_motion_database

Ponzo FC, Di Cesare A, Nigro D, Vulcano A, Mazza F, Dolce M, Moroni C (2012) Jet-pacs project: dynamic experimental tests and numerical results obtained for a steel frame equipped with hysteretic damped chevron braces. J Earthq Eng 16(5):662-685

Ryan KL, Chopra AK (2006) Estimating seismic demands for isolation bearings with building overturning effects. J Struct Eng 132:1118-1128

Ryan KL, Kelly JK, Chopra AK (2004) Experimental observation of axial load effects in isolation bearings. In: Proceedings of the 13th World Conference on Earthquake Engineering, Vancouver (Canada), paper No. 1707 